\title{
Treating patients with medically resistant epilepsy
}

\author{
Gregory L. Krauss, MD \\ Michael R. Sperling, MD
}

\section{Summary}

Recent evidence suggests that medically resistant epilepsy can be identified if seizures persist despite adequate doses of 2 appropriate first-line antiepileptic drugs (AEDs). Patients with medically resistant epilepsy should have their seizures carefully characterized in order to confirm their diagnosis, select treatment, and assist in determining prognosis. Patients should be counseled about factors that aggravate epilepsy and the importance of adhering to treatments. Physicians should carefully inquire about side effects and alter therapy to eliminate or minimize these symptoms. Uncontrolled seizures cause injuries, disability, and increased mortality, so surgery should be considered as soon as seizures are proven to be medically resistant. Patients with incomplete response to AEDs and who are not surgical candidates may benefit from additional medication trials or from palliative nonmedical therapies, such as vagal nerve stimulation.

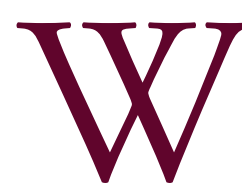

hat is medically resistant epilepsy? Medically resistant epilepsy would seem to be a self-evident term, referring to patients whose seizures persist

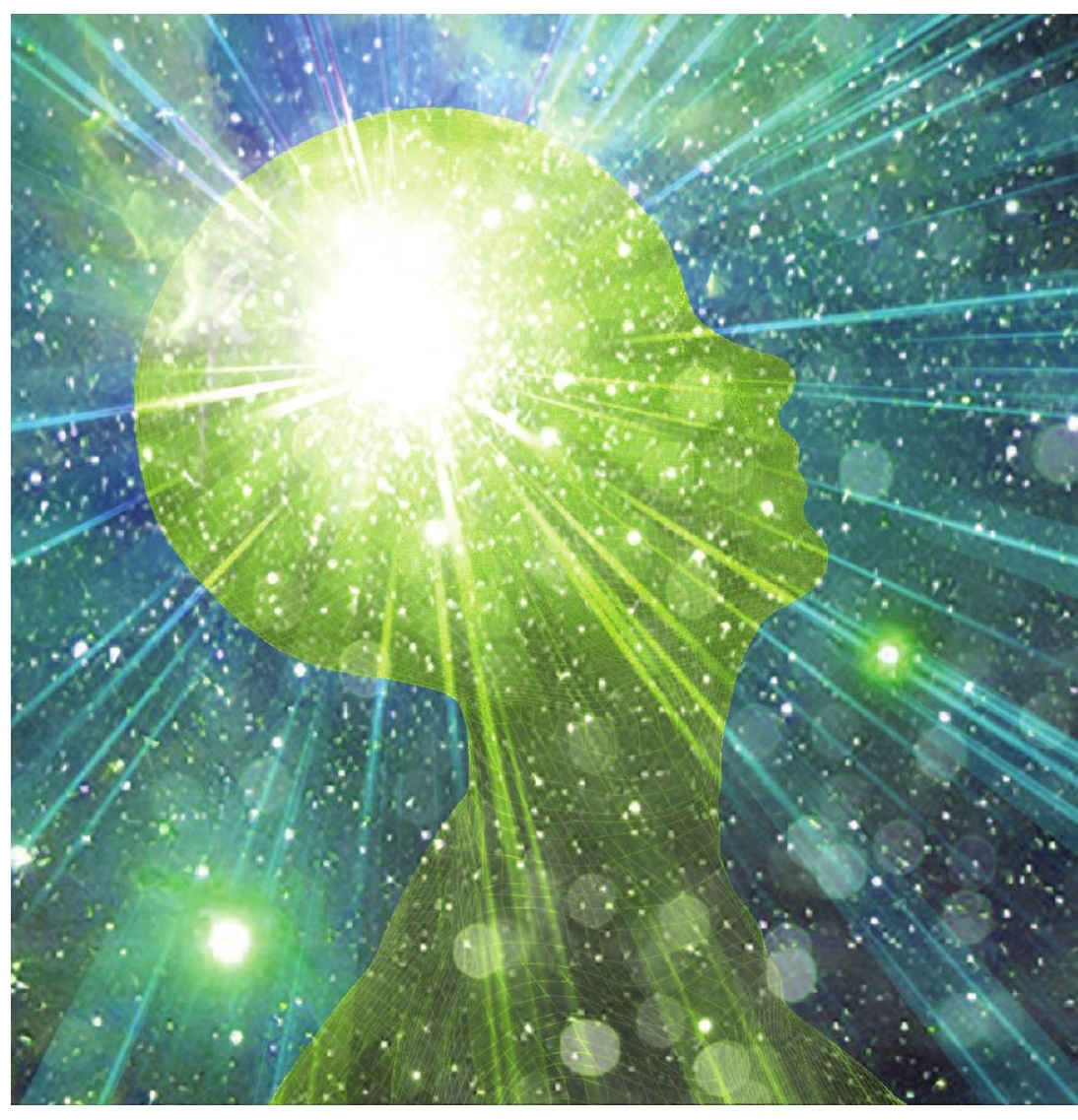
despite using antiepileptic drugs (AEDs). The definition, however, relies as much upon pharmacologic efficacy and physician treatment skills as the underlying biology and natural history of epilepsy. One might have hoped that the development of nearly a dozen new drugs for epilepsy in the 1990s and 2000s would have simplified this definition. Unfortunately, while many newer drugs have superior pharmacokinetic and side-effect profiles than older AEDs, they possess the same degree of effectiveness. These AEDs rarely stop seizures once older agents have failed. Hence, until innovative pharmaceutical approaches yield better response rates, we must conclude that medical resistance is biologically determined and innate in some forms of epilepsy.

Johns Hopkins University (GLK), Baltimore; and Thomas Jefferson University (MRS), Philadelphia.

Correspondence to: gkrauss@jhmi.edu 
Drug-resistant epilepsy has been defined as the "failure of adequate trials of 2 tolerated, appropriately chosen and used antiepileptic drug schedules (whether as monotherapy or in combination) to achieve sustained seizure freedom." This operational definition, established by an International League Against Epilepsy commission, ${ }^{1}$ relies upon the observation that adults and children rarely achieve sustained seizure freedom once 2 agents have failed to control seizures. ${ }^{2-4}$ The definition includes the important requirement that the drugs must be both appropriate for the patient's seizure type and tolerated at therapeutic doses. For example, failure of ethosuximide to control complex partial seizures is not a valid drug failure since ethosuximide is ineffective for focal seizures. Similarly, a suitable dose must be used, so the patient who only tolerates a subtherapeutic dose of a particular AED cannot be considered to have failed to respond to that drug. Finally, the drug must be given a reasonable chance to work, and an excessively brief course of treatment is not adequate. Careful attention to these requirements should prevent inappropriate diagnosis of drug resistance.

\section{Why is it important to recognize medically resistant epilepsy?}

Patients with frequent, severe seizures experience high rates of psychosocial disabilities, including undereducation, underemployment and unemployment, impaired socialization, and psychiatric disturbances. ${ }^{5,6}$ They also have increased medical morbidity, with higher than expected injury rates and high mortality rates. ${ }^{6}$ Attaining seizure control by nonmedical means can reverse some of the disability, morbidity, and mortality of refractory epilepsy. ${ }^{7,8}$ Failure to acknowledge drug resistance may prevent patients from receiving alternative treatments that might be effective, such as epilepsy surgery.

One must consider seizure type, seizure effects, and epilepsy syndrome when thinking about drug-resistant epilepsy as they influence whether new medications or alternative therapies are needed. What kinds of seizures merit more aggressive therapy? The most common types are seizures producing loss of awareness, which can be disabling and pose medical and psychosocial risk. Uncontrolled complex partial seizures, and, especially, tonic-clonic seizures are associated with increased mortality, from sudden unexpected death in epilepsy (SUDEP) and other causes; this risk exceeds the risk of more aggressive interventions. Some seizures without loss of consciousness might be sufficiently disturbing to warrant pursuing new treatments as well (e.g., seizures producing vomiting or intense fear).

Seizures that cause injury (e.g., falling) also must be taken more seriously. Seizures with stigmatizing behavior (e.g., incontinence or disrobing) pose more difficulty than inconspicuous attacks. Similarly, seizures followed by profound postictal effects (e.g., extreme fatigue or sleepiness, cognitive impairment, or psychiatric disturbances) merit more aggressive therapy. By contrast, minor nondisabling seizures without these features might be deemed medically resistant, but are insufficiently problematic to warrant pursuing further diagnostic evaluation or therapy. The epilepsy syndrome matters, as well. One must establish whether the syndrome is static or progressive (e.g., progressive myoclonus epilepsy or Rasmussen syndrome) and whether it is potentially surgically remediable (e.g., mesial temporal sclerosis). Response to medication must always be put in context, considering what kind of seizures and epilepsy are present prior to making a decision about the next steps. ${ }^{9}$

\section{Steps to accurately diagnose and treat medically resistant} epilepsy Confirm the patient has epilepsy (tables 1 and 2) Seizures may not respond to AEDs if the patient does not have epilepsy. Common imitators of seizures include convulsive syncope (severe syncope causing jerking or shaking), psychogenic nonepileptic seizures (seizure-like behaviors), pain or panic reactions, and dissociative states. ${ }^{10}$ Most seizure types and epilepsy can be accurately diagnosed by the presence of their typical clinical features. The EEG can often help confirm the seizure type and MRI is important to identify underlying causes for seizures. It is important to collect a careful history of key clinical features of seizures 
Table 1 Evaluating and treating medically resistant epilepsy

\section{Identifying epilepsy and seizure types vs alternative disorders}

Epilepsy

- Partial-onset seizures: simple partial, complex partial, secondary generalized tonic clonic

- Primary generalized epilepsy: childhood and juvenile absence, myoclonic, tonic clonic

- Severe symptomatic (multifocal epilepsy, Lennox-Gastaut) or progressive seizure types

Alternative diagnosis

- Syncope and convulsive syncope

- Psychogenic nonepileptic seizures

- Pain reactions, panic symptoms, dissociative episodes and other psychiatric states, sleep disorders, narcolepsy

Clues: Careful description of episodes by patient and observers (duration, prodromal symptoms, responsiveness and behaviors, recovery duration and symptoms)

from both the patient and observers. Here is a helpful list of some of the common features of seizures: the presence of warning symptoms (gastric or psychic auras are common with complex partial seizures); the presence of activity arrest, altered awareness, or diminished responsiveness during the seizure; the duration of the episodes (most epileptic seizures last less than 4 minutes); and whether the recovery period matches the severity of the seizure (usually several minutes for mild complex partial seizures, up to hours following tonic-clonic seizures). ${ }^{11}$ Complex partial seizures are often preceded by brief epigastric or psychic (e.g., fear, déjà vu) auras and may be associated with activity arrest or with confusion and typical motor automatisms, such as fumbling, chewing, mild limb shaking, or head/eye deviation with postictal confusion. Tonic-clonic seizures are major convulsive episodes with severe stiffening and shaking and postictal confusion, often with tongue biting and postictal headaches.

In contrast to seizures, syncopal episodes often occur when patients are standing or changing posture, particularly when dehydrated or exhausted. Many patients become pale, briefly lightheaded or dizzy, and then collapse. Patients may experience brief myoclonic jerks, or even full convulsions if severely hypotensive. ${ }^{12}$ Patients often have nausea and feel exhausted after a syncopal episode-less common features of seizures. Patients with psychogenic nonepileptic seizures ("pseudoseizures") often have multiple features which are atypical for epileptic seizures, such as preictal headache, eye closure or fluttering, asynchronous or writhing movements, a rapid start-stop-start pattern of seizures, prolonged confusion, and stress triggers. ${ }^{13}$ Psychogenic seizures often remain misdiagnosed when normal variant or drowsy EEG patterns are interpreted as epileptiform discharges. ${ }^{14}$ Patients with pain reactions or panic reactions often have symptoms which precede their seizure-like behaviors. Uncertain diagnoses usually can be clarified with video-EEG.

Determine treatment response (table 3) Patients who fail treatment with high doses of several first-line AEDs appropriate for their seizure type have medication-resistant epilepsy. Some patients, however, appear to have drug resistance, but have not tolerated several AEDs due to multiple allergic reactions or due to drug side effects. These patients can usually find alternative therapies which they can tolerate. AEDs infrequently associated with allergic reactions are levetiracetam, topiramate, gabapentin, and divalproex. ${ }^{15}$ Many patients, particularly the elderly, are sensitive to CNS-related medication side effects, such as dizziness, somnolence, and imbalance. ${ }^{16}$ They often tolerate and respond to treatment with standard AEDs if AEDs are titrated very slowly to low doses. ${ }^{17}$ AEDs associated with a low prevalence of dizziness and 
Table 2 Distinguishing seizures and syncope and other common causes of loss of awareness $^{32-34}$

\begin{tabular}{|c|c|c|c|}
\hline & Seizures & Syncope & $\begin{array}{l}\text { Other: psychogenic } \\
\text { seizures, pain reactions, } \\
\text { dissociative }\end{array}$ \\
\hline $\begin{array}{l}\text { Premonitory } \\
\text { symptoms }\end{array}$ & $\begin{array}{l}\text { Psychic or epigastric } \\
\text { aura if partial-onset } \\
\text { seizures }\end{array}$ & Lightheadedness & $\begin{array}{l}\text { Often prolonged, pain } \\
\text { may precede }\end{array}$ \\
\hline $\begin{array}{l}\text { Accompanying } \\
\text { symptoms/signs }\end{array}$ & $\begin{array}{l}\text { Activity arrest, } \\
\text { unresponsiveness, } \\
\text { cyanosis if convulsive }\end{array}$ & $\begin{array}{l}\text { Diaphoresis, pallor, heat } \\
\text { sensation, nausea }\end{array}$ & Panic, anxiety, pain \\
\hline Motor signs & $\begin{array}{l}\text { Rhythmic movements, } \\
\text { focal head/eye } \\
\text { version, chewing eyes } \\
\text { often open, tongue } \\
\text { biting if convulsive }\end{array}$ & $\begin{array}{l}\text { Irregular myoclonus after } \\
\text { onset, brief convulsion if } \\
\text { severe (convulsive } \\
\text { syncope) }\end{array}$ & $\begin{array}{l}\text { Atypical or nonphysiologic } \\
\text { movements (asymmetric } \\
\text { limb jerks, eyelid } \\
\text { fluttering), eyes often } \\
\text { closed }\end{array}$ \\
\hline Duration & $\begin{array}{l}\text { Typically } 20 \text { seconds } \\
\text { to } 3 \text { minutes }\end{array}$ & Seconds & $\begin{array}{l}\text { Variable, often prolonged } \\
\text { (many minutes to hours) }\end{array}$ \\
\hline Recovery & $\begin{array}{l}\text { Rapid to gradual } \\
\text { recovery of alertness }\end{array}$ & $\begin{array}{l}\text { Rapid (disorientation } \\
<5 \text { minutes), general } \\
\text { exhaustion }\end{array}$ & $\begin{array}{l}\text { Typically rapid, repetitive } \\
\text { start/stop common }\end{array}$ \\
\hline $\begin{array}{l}\text { Common } \\
\text { precipitants }\end{array}$ & $\begin{array}{l}\text { None, may vary with } \\
\text { sleep or arousal, } \\
\text { catamenial pattern in } \\
\text { women }\end{array}$ & $\begin{array}{l}\text { Sitting or standing, } \\
\text { dehydration, exhaustion } \\
\text { autonomic activation } \\
\text { (pain or specific stress } \\
\text { trigger) }\end{array}$ & $\begin{array}{l}\text { General emotional and } \\
\text { physical stress, pain }\end{array}$ \\
\hline $\begin{array}{l}\text { Common } \\
\text { associated } \\
\text { conditions }\end{array}$ & $\begin{array}{l}\text { Prior brain injury or } \\
\text { disorders }\end{array}$ & Presyncope & $\begin{array}{l}\text { Psychiatric and cognitive } \\
\text { disorders (mood disorders, } \\
\text { anxiety/panic, } \\
\text { postconcussive syndrome) }\end{array}$ \\
\hline Diagnostic tests & $\begin{array}{l}\text { Abnormal EEG, video } \\
\text { EEG }\end{array}$ & ECG, tilt table & $\begin{array}{l}\text { Normal EEG, video EEG, } \\
\text { Personality Assessment } \\
\text { Inventory }\end{array}$ \\
\hline Disorders & $\begin{array}{l}\text { Generalized seizures, } \\
\text { partial-onset seizures, } \\
\text { single seizures }\end{array}$ & $\begin{array}{l}\text { Vasovagal, orthostatic } \\
\text { hypotension, cardiac } \\
\text { syncope (arrhythmia or } \\
\text { loss of cardiac output) }\end{array}$ & $\begin{array}{l}\text { Emotional and cognitive } \\
\text { disorders }\end{array}$ \\
\hline
\end{tabular}

similar symptoms can also be used, such as lamotrigine and levetiracetam. ${ }^{18}$ Patients often have dose-limiting CNS-related side effects due to combined effects of AEDs—patients can often successfully convert rapidly between the old and new medications.

Identify symptomatic causes for medically resistant epilepsy and screen for aggravating factors Patients with uncontrolled partial-onset seizures may benefit from highresolution MRI with thin-section coronal fluid-attenuated inversion recovery (FLAIR) imaging to identify focal lesions associated with seizures, such as cortical dysgenesis, vascular abnormalities, and tumors. Cutaneous fibromas, renal lipomas, ataxia, ophthalmologic and other abnormalities can be clues suggesting possible genetic and developmental disorders associated with epilepsy. Patients with difficult-to-control seizures often have seizures triggered by severe stress and exhaustion, illness, sleep deprivation, or alcohol abuse. These factors are especially important triggers of generalized seizures. ${ }^{19}$ Some patients have seizures because they regularly miss or do not take their AED doses-this may be an expression of abnormal coping or denial of their disorder or can represent a lack of understanding of the importance of maintaining steady AED concentrations to prevent seizures. 


\section{Table 3 Possible strategies for treating medically resistant epilepsy}

\section{Partial-onset seizures}

After failing 2 monotherapy trials with first-line AEDs, e.g., lamotrigine, extended-release carbamazepine, levetiracetam, oxcarbazepine

- Additional monotherapy trial if high doses of previous AEDs poorly tolerated

- Adjunctive treatment with a complementary AED

- Match AED to patient profiles and needs, e.g., women of childbearing age, elderly patients, comorbid conditions (e.g., mood disorders, obesity, treatment interactions)

- Minimize combination drug side effects (e.g., dizziness with high doses of oxcarbazepine and lacosamide) and drug interactions (e.g., increased free carbamazepine concentrations with divalproex)

- AED options include topiramate, lacosamide, zonisamide, divalproex, phenytoin

- Consider nonmedical therapy: surgery screening, vagal nerve stimulation, ketogenic/Atkins diet

- Orphan and third-line AED options: clobazam, vigabatrin, barbiturates

\section{Primary generalized epilepsy}

After failing 2 monotherapy trials with first-line AEDs, e.g., divalproex, levetiracetam, lamotrigine (ethosuximide for childhood/juvenile absence epilepsy)

- Consider adjunctive therapy and possible conversion to monotherapy: topiramate, zonisamide

- Additional adjunctive therapies: clonazepam, acetazolamide, clobazam

Severe symptomatic forms of epilepsy: multifocal, typically multiple seizure types

After failing 2 monotherapy trials with first-line AEDs, e.g., divalproex, levetiracetam, lamotrigine, carbamazepine

- Consider adjunctive therapy using combinations of broad and narrow spectrum AEDs, e.g., topiramate and divalproex, carbamazepine and levetiracetam, levetiracetam and lacosamide, divalproex and rufinamide

- Nonmedical therapy: vagus nerve stimulation, ketogenic/Atkins diet therapy

- Third-line adjunctive therapies: clonazepam, clobazam, felbamate

Corpus callosotomy (anterior $66 \%$ to $80 \%$ )

Abbreviation: AED = antiepileptic drug

Many patients take AEDs irregularly due to concerns about AED side effects or of pregnancy risks. These problems are usually resolved by reviewing the diagnosis and treatment options with patients along with a plan for monitoring for specific drug side effects, such as irritability with levetiracetam or weight gain with divalproex or concentration difficulty (with all AEDs). Careful attention to ameliorating side effects, use of weekly pill boxes, smart phone alarms, coupling dosing with dressing or other regular daily activities, and use of extended-release formulations to reduce dosing frequency can all improve drug adherence.

\section{Treating medically resistant epilepsy}

Three case studies illustrate key principles in managing drug-resistant epilepsy.

Case 1 A 22-year-old woman, with an initial tonic-clonic seizure at age 16, now has 4 seizures in 2 months, despite treatment with levetiracetam $1,500 \mathrm{mg} /$ day. She previously had seizures and dizziness during treatment with oxcarbazepine $1,800 \mathrm{mg} /$ day. A previous EEG was normal. She and her mother describe episodes with features typical of complex partial seizures: a psychic aura lasting several seconds followed by sudden 30- to 90-second periods of confusion with chewing 


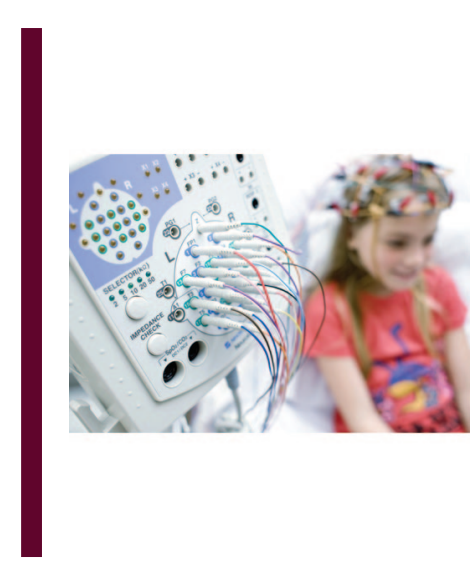

Patients with uncontrolled

partial-onset seizures may

benefit from high-resolution MRI

with thin-section coronal FLAIR

imaging to identify focal lesions

associated with seizures, such

as cortical dysgenesis, vascular

abnormalities, and tumors.

motions and fumbling. Detailed questioning elicits a history of a prolonged febrile seizure at age 1 year. A previous MRI is reportedly normal.

Analysis She has typical complex partial seizures - chewing suggests temporal lobe involvement. This is confirmed by a new interictal EEG, which shows left temporal sharp waves. She strongly desires to be free of seizures in order to drive and to minimize future pregnancy risks. We can consider increasing the dose of levetiracetam or adding an AED approved for adjunctive treatment of partial-onset seizures. A wide range of other treatment options include lamotrigine, extended-release carbamazepine, lacosamide, zonisamide, and pregabalin. ${ }^{20} \mathrm{Con}$ version to lamotrigine monotherapy is approved and has low risk for birth malformations. Divalproex (valproic acid) is a suboptimal AED for her, since it is associated with a $10 \%$ risk of birth defects and with weight gain. She is a student and could be treated with low doses of topiramate but may not wish to risk cognitive impairment with high doses. However, only a small percentage of patients who fail to respond to 2 or more AEDs become seizure-free. ${ }^{2,21}$ Most patients with medial temporal lobe epilepsy become seizure-free after anterior temporal lobectomy or amygdalohippocampectomy. ${ }^{22}$

After discussing medical and nonmedical treatment options, she is referred for surgical screening with high-resolution MRI and video-EEG monitoring and begins lamotrigine. Coronal FLAIR MRI demonstrates probable left mesial temporal sclerosis and video-EEG shows left temporal seizure onset, suggesting she is a good surgical candidate. She continues to experience complex partial seizures while taking lamotrigine and then has a left anterior temporal lobectomy, subsequently entering remission. She has a minor decline in verbal memory after surgery and is able to obtain a driver's license. When the MRI shows mesial temporal sclerosis and preoperative verbal memory is impaired, chances are small that surgery will cause a severe or disabling cognitive deficit.

Case 2 A 21-year-old man has had 3 tonic-clonic seizures in the past year despite treatment with lamotrigine $600 \mathrm{mg} /$ day and previous treatment with levetiracetam 2,500 mg/day. He had his first tonic-clonic seizure at age 15, while playing video games. A brain MRI done prior to referral was normal. There is no family history of seizures.

Analysis Although referred for his tonic-clonic seizures, when asked, the patient reports having occasional clusters of bilateral arm and neck jerks in the morning. With myoclonic and tonic-clonic seizures, he is now diagnosed with probable juvenile myoclonic epilepsy (JME). This is confirmed by an EEG showing interictal $5 \mathrm{~Hz}$ generalized polyspike and slow wave bursts. His treatment adherence is demonstrated by a lamotrigine serum concentration of 14 $\mathrm{mg} / \mathrm{L}$ (typical target range 4 to $10 \mathrm{mg} / \mathrm{L}$ ). His seizures do not appear to be provoked by lifestyle factors such as sleep deprivation or excessive alcohol use. His seizures interfere with 
In countries with full financial resources, expensive AEDs and surgery are widely available, but lack of training to make the appropriate diagnosis and referral to an epilepsy center leaves many patients with

\section{inadequate treatment.}

work and driving. Seizures are usually controlled in JME so continued medical manipulation is worthwhile. ${ }^{23}$

He begins treatment with divalproex and has 2 seizures on a dose of $750 \mathrm{mg} / \mathrm{day} .{ }^{24} \mathrm{He}$ has no seizures on divalproex $1,500 \mathrm{mg} /$ day monotherapy in the next year; however, he develops marked weight gain. He has remained seizure-free since switching to zonisamide $300 \mathrm{mg} /$ day. ${ }^{25}$ In this case, ascertainment of the correct diagnosis leads the physician to trying more medication, with a reasonable prospect of achieving a favorable response.

Case 3 A 25-year-old man with moderate intellectual disability and cerebral palsy has multiple daily seizures. Most are brief tonic and tonic/atonic seizures with bilateral arm and leg stiffening, often followed by brief loss of body tone; he also has several seizures each day with unresponsiveness and asymmetric bilateral shaking, often with left facial contraction. He occasionally falls and is injured during seizures and must wear a helmet. He is largely confined to a wheelchair. He is treated with divalproex $500 \mathrm{mg}$ TID $(98 \mathrm{mg} / \mathrm{L})$ and clonazepam $0.5 \mathrm{mg}$ TID. He previously had frequent seizures or was sedated during multiple AED trials, including phenytoin, felbamate, topiramate, lamotrigine, zonisamide, and rufinamide. He had fewer seizures while taking levetiracetam, but displayed aggressive behavior. An MRI showed mild scattered bilateral subcortical T2 abnormalities. EEG shows frequent independent left and right hemisphere and bilateral slow spike and wave bursts, along with mild diffuse slowing.

Analysis This patient fulfills criteria for diagnosis of Lennox-Gastaut syndrome. Patients with symptomatic generalized epilepsy often exhibit multiple seizures types, including tonic, complex partial, and tonic-clonic seizures along with significant cognitive impairment. His clinical condition provides evidence for diffuse brain injury and he is not a candidate for focal resective surgery. He has not responded to first- and second-line AEDs and will likely require AED polytherapy for the foreseeable future. He may benefit from intermittent adjuvant benzodiazepine treatment, preferably using nonsedating doses, for acute transient seizure exacerbations. He is a candidate for palliative therapy with vagal nerve stimulation (VNS) ${ }^{26}$ and also may benefit from clobazam therapy. ${ }^{27,28} \mathrm{He}$ may also cooperate with treatment with the ketogenic/Atkins $\operatorname{diet}^{29} \mathrm{An}$ anterior $(66 \%$ to $80 \%)$ corpus callosotomy is also a good option, and offers the greatest chance for substantial reduction in seizure frequency, especially for the tonic and atonic seizures, though it also has the highest morbidity of the treatments mentioned. ${ }^{30}$

To minimize his need for emergency department visits, his caregivers were given lorazepam Intensol $2 \mathrm{mg} / \mathrm{mL}$ sublingual solution to treat acute repetitive seizures and a diazepam rectal formulation to treat occasional prolonged ( $>5$ minutes) seizures. Lorazepam Intensol is only approved for treating anxiety, but has high bioavailability and is frequently used at 1 to $2 \mathrm{mg}$ sublingual doses for acute seizure treatment. Patients with severe symptomatic epilepsy need careful monitoring for psychiatric and behavioral symptoms associated with underlying brain injury, seizures, and AED therapy. The patient had clobazam $10 \mathrm{mg}$ TID substituted for clonazepam with moderate seizure reduction; he subsequently had VNS placed. He now has several minor myoclonic and brief focal seizures per week. He no longer falls 
during his seizures and now is permitted to walk independently in his day and residential program.

\section{Limitations in care}

In countries where resources limit access to health care, the above diagnostic considerations still apply, though the subsequent course of action might differ once a diagnosis of medically resistant seizures is made. Even if patients cannot afford the newest AEDs, inexpensive drugs are equally potent. Should inexpensive drugs prove intolerable, then financial limitations may prevent adequate treatment. Palliative and potentially curative options such as surgery might not be available. In countries with full financial resources, expensive AEDs and surgery are widely available, but lack of training to make the appropriate diagnosis and referral to an epilepsy center leaves many patients with inadequate treatment. In these countries, the wider selection of AEDs conveys advantages with regard to limiting adverse drug side effects and expanded treatment options. Patients with medically resistant epilepsy should be counseled not to drive and often need employment, educational, and psychological support. ${ }^{31}$

\section{REFERENCES}

1. Kwan P, Arzimanogluou A, Berg AT, et al. Definition of drug resistant epilepsy: Consensus proposal by the ad hoc Task Force of the ILAE Commission on Therapeutic Strategies. Epilepsia 2010;51:10691077.

2. Kwan P, Brodie MJ. Early identification of refractory epilepsy. N Engl J Med 2000;342:314-319.

3. Mohanraj R, Brodie MJ. Diagnosing refractory epilepsy: response to sequential treatment schedules. Eur J Neurol 2006;13:277-282.

4. Arts WF, Brouwer OF, Peters AC, et al. Course and prognosis of childhood epilepsy: 5-year follow-up of the Dutch study of epilepsy in childhood. Brain 2004;127:1774-1784.

5. Jacoby A, Baker GA, Steen N, Potts P, Chadwick DW. The clinical course of epilepsy and its psychosocial correlates: findings from a U.K. community study. Epilepsia 1996;37:148-161.

6. Sperling MR. The consequences of uncontrolled epilepsy. CNS Spectr 2004;9:98-109.

7. Sperling MR, Harris A, Nei M, Liporace JD, O’Connor MJ. Mortality after epilepsy surgery. Epilepsia 2005;46:49-53.

8. Zarroli K, Tracy JI, Nei M, Sharan A, Sperling MR. Employment after anterior temporal lobectomy. Epilepsia 2011;52:925-931.

9. Sander JW. The use of antiepileptic drugs: principles and practice. Epilepsia 2004;45:28-34.

10. Grubb BP, Gerard G, Roush K, et al. Differentiation of convulsive syncope and epilepsy with head-up tilt testing. Ann Intern Med 1991;115:871-876.

11. Theodore WH, Porter RJ, Albert P, et al. The secondarily generalized tonic-clonic seizure. Neurology 1994;44:1403-1407.

12. Wieling W, Thijs RD, van Dijk N, et al. Symptoms and signs of syncope: a review of the link between physiology and clinical clues. Brain 2009;132:2630-2642.

13. Syed TU, LaFrance Jr WC, Kahriman ES, et al. Can semiology predict psychogenic nonepileptic seizures? A prospective study. Ann Neurol 2011;69:997-1004.

14. Krauss GL, Abdallah A, Lesser R, et al. Clinical and EEG features of patients with EEG wicket rhythms misdiagnosed with epilepsy. Neurology 2005;64:1879-1883.

15. Arif H, Buchsbaum R, Weintraub D, et al. Comparison and predictors of rash associated with 15 antiepileptic drugs. Neurology 2007;68:1701-1709.

16. Ramsay RE, Rowan AJ, Pryor FM. Special considerations in treating the elderly patient with epilepsy. Neurology 2004;62(suppl 2):S24-S29.

17. Rowan AJ, Ramsay RE, Collins JF, et al. New onset geriatric epilepsy: a randomized study of gabapentin, lamotrigine, and carbamazepine. Neurology 2005;64:1868-1873.

18. Zaccara G, Messori A, Cincotta M, Burchini G. Comparison of the efficacy and tolerability of new antiepileptic drugs: what can we learn from long-term studies? Acta Neurol Scand 2006;114:157-168.

19. Marson AG, Al-Kharusi AM, Alwaidh M, et al. The SANAD study of effectiveness of valproate, lamotrigine, or topiramate for generalised and unclassifiable epilepsy: an unblended randomised controlled trial. Lancet 2007;369:1016-1026.

20. Marson AG, Al-Kharusi AM, Alwaidh M, et al. The SANAD study of effectiveness of carbamazepine, gabapentin, lamotrigine, oxcarbazepine, or topiramate for treatment of partial epilepsy: an unblended randomised controlled trial. Lancet 2207;369:1000-1015.

21. French JA, Kanner AM, Bautista J, et al. Efficacy and tolerability of the new antiepileptic drugs II: treatment of new onset epilepsy: Report of the Therapeutics and Technology Assessment Subcommittee 
and Quality Standards Subcommittee of the American Academy of Neurology and the American Epilepsy Society. Neurology 2004;62:1261-1273.

22. Wiebe S, Blume WT, Girvin JP, et al. A randomized, controlled trail of surgery for temporal-lobe epilepsy. N Engl J Med 2001;345:311-318.

23. Nicolson A, Appleton RE, Chadwick DW, Smith DF. The relationship between treatment with valproate, lamotrigine, and topiramate and the prognosis of the idiopathic generalised epilepsies. J Neurol Neurosurg Psychiatry 2004;75:75-79.

24. Nicolson A, Marson AG. When the first antiepileptic drug fails in a patient with juvenile myoclonic epilepsy. Pract Neurol 2010;10:208-218.

25. Mantoan L, Walker M. Treatment options in juvenile myoclonic epilepsy. Curr Treat Options Neurol 2011;13:355-370.

26. Englot DJ, Chang EF, Auguste KI. Vagus nerve stimulation for epilepsy: a meta-analysis of efficacy and predictors of response. J Neurosurg Epub 2011.

27. Conry JA, Ng YT, Paolicchi JM, et al. Clobazam in the treatment of Lennox-Gastaut syndrome. Epilepsia 2009;50:1158-1166.

28. Montengero M, Arif H, Edumund N, et al. Efficacy of clobazam as add-on therapy for refractory epilepsy: experience at a US epilepsy center. Clin Neuropharmacol 2008;31:333-338.

29. Kossoff EH, Rho JM. Ketogenic diets: evidence for short- and long-term efficacy. Neurotherapeutics 2009;6:406-414.

30. Asadi-Pooya A, Sharan A, Nei M, Sperling MR. Corpus callosotomy. Epilepsy Behav 2008;13:271278.

31. Jacoby A, Baker GA. Quality-of-live trajectories in epilepsy: a review of the literature. Epilepsy Behav 2008;12:557-571.

32. Sheldon R, Rose S, Ritchie D, et al. Historical criteria that distinguish syncope from seizures. J Am Coll Cardiol 2002;40:142-148.

33. Bergfeldt L. Differential diagnosis of cardiogenic syncope and seizure disorders. Heart 2003;89:353358.

34. Testa M, Lesser RP, Krauss GK, Brandt J. Personality Assessment Inventory among patients with psychogenic seizures and those with epilepsy. Epilepsia 2011;52:84-88.

\section{DISCLOSURES}

Dr. Krauss serves as Vice President for the Epilepsy Study Consortium and on a safety monitoring board for Lundbeck Inc.; has received funding for travel from Eisai Inc. and a speaker honorarium from UCB; serves as Clinical Science Editor for Epilepsy Currents; receives publishing royalties for The Johns Hopkins Digital EEG Atlas (Johns Hopkins University Press, 2006, 2011); and receives research support for UCB, Eisai Inc., Sepracor Inc., Vertex Pharmaceuticals, Novartis, the NIH/NIA, and the Epilepsy Research Foundation. Dr. Sperling serves on scientific advisory boards for UCB and Vertex Pharmaceuticals; has received a speaker honorarium from UCB; serves as an Associate Editor for Epilepsia; serves as a consultant for Sunovion Pharmaceuticals; has served on speakers' bureaus for UCB and Pfizer Inc; and receives research support from UCB, Marinus Pharmaceuticals, Inc., Sunovion Pharmaceuticals, Sepracor Inc., Eisai Inc., Novartis, Lundbeck Inc., Vertex Pharmaceuticals, NeuroPace, Inc., Medtronic, Inc., and the NIH. 


\section{Related articles from other AAN physician and patient resources}

Neurology ${ }^{\circledR} \quad \bullet \quad$ www.neurology.org

Self-treatment of benign paroxysmal positional vertigo: Semont maneuver vs Epley procedure. July 13, 2004;63:150-152.

Patient Page: Responsive neurostimulation for the treatment of seizures that do not respond to medication.

September 27, 2011;77:e79-e81.

Responsive cortical stimulation for the treatment of medically intractable partial epilepsy. September 27, 2011;77:1295-1304.

Randomized, double-blind, placebo-controlled trial of ezogabine (retigabine) in partial epilepsy. May 3, 2011;76:1555-1563.

Quality improvement in neurology: AAN epilepsy quality measures: Report of the Quality Measurement and Reporting Subcommittee of the American Academy of Neurology. January 4, 2011;96:94-99.

\section{Continuum ${ }^{\circledR}$}

- www.aan.com/go/elibrary/continuum

Epilepsy surgery and electronic devices. June 2010;16:179-198.

\section{Neurology Today ${ }^{\circledR} \quad$ - www.neurotodayonline.com}

Responsive cortical stimulation found effective for intractable partial epilepsy.

September 15, 2011;11:25-27. 


\section{Neurology ${ }^{\circ}$ Clinical Practice}

Treating patients with medically resistant epilepsy

Gregory L. Krauss and Michael R. Sperling

Neurol Clin Pract 2011;1;14-23

DOI 10.1212/CPJ.0b013e31823d07d1

This information is current as of December 1, 2011

\section{Updated Information \& \\ Services}

References

Citations

Subspecialty Collections

Errata

Permissions \& Licensing

Reprints including high resolution figures, can be found at: http://cp.neurology.org/content/1/1/14.full.html

This article cites 33 articles, 9 of which you can access for free at: http://cp.neurology.org/content/1/1/14.full.html\#\#ref-list-1

This article has been cited by 2 HighWire-hosted articles: http://cp.neurology.org/content/1/1/14.full.html\#\#otherarticles

This article, along with others on similar topics, appears in the following collection(s):

All Clinical Neurology

http://cp.neurology.org//cgi/collection/all_clinical_neurology

Multiple sclerosis

http://cp.neurology.org//cgi/collection/multiple_sclerosis

An erratum has been published regarding this article. Please see next page or:

/content/2/1/4.2.full.pdf

Information about reproducing this article in parts (figures,tables) or in its entirety can be found online at:

http://cp.neurology.org/misc/about.xhtml\#permissions

Information about ordering reprints can be found online: http://cp.neurology.org/misc/addir.xhtml\#reprintsus

Neurol Clin Pract is an official journal of the American Academy of Neurology. Published continuously since 2011, it is now a bimonthly with 6 issues per year. Copyright Copyright $\odot 2011$ by AAN Enterprises, Inc.. All rights reserved. Print ISSN: 2163-0402. Online ISSN: 2163-0933.

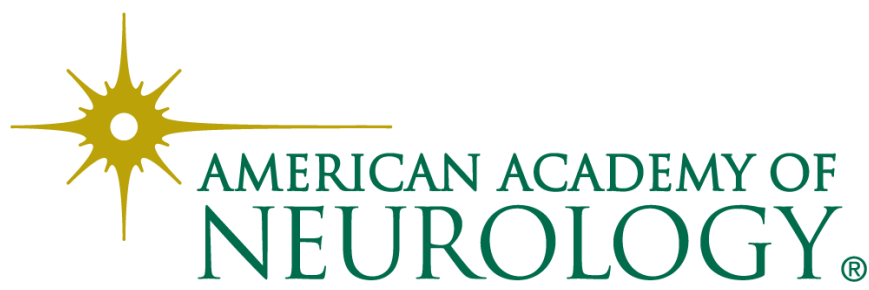


involvement likely including the thalami bilaterally to also account for her coma. Furthermore, if these lesions were indeed present, they would likely be picked up on CT scan, given that her symptomatology was progressive for 3 days prior to obtaining the study. Based on our experience, the clinical recovery began too rapidly for metabolic encephalopathies causing changes in the basal ganglia.

Disclosures: See original article for full disclosure list.

Correspondence to: Hocker.Sara@mayo.edu

1. Hocker S, Rabinstein AA. Cefepime neurotoxicity can mimic postanoxic coma with myoclonic status epilepticus. Neurol Clin Pract 2011;1:73-74.

2. Fishbain JT, Monahan TP, Canonico MM. Cerebral manifestations of cefepime toxicity in a dialysis patient. Neurology 2000;55:1756-1757.

3. Dixit S, Kurle P, Buyan-Dent L, Sheth RD. Status epilepticus associated with cefepime. Neurology 2000;54:2153-2155.

\section{CORRECTION}

Neurogenetics: Five new things

In the article "Neurogenetics: Five new things" by S. Jayadev et al. (Neurology ${ }^{\circledR}$ Clinical Practice 2011;1:41-48), there is an omission in figure 2, which should read "The copyright for this figure is held by the University of Washington.” The editorial staff regrets the omission.

\section{CORRECTION}

Treating patients with medically resistant epilepsy

In the article "Treating patients with medically resistant epilepsy" by Gregory L. Krauss and Michael R. Sperling (Neurology ${ }^{\circledR}$ Clinical Practice 2011;1:14-23), there is an error in the second to last line in table 3. "Corpus callosotomy (anterior 66\% to 80\%)" should be listed as another bullet point under treatment for "Severe symptomatic forms of epilepsy" below "Third-line adjunctive therapies." The publisher regrets the error. 